\title{
Role of service encounter and physical environment performances, novelty, satisfaction, and affective commitment in generating cruise passenger loyalty
}

\begin{abstract}
This research developed a theoretical model explaining the relationship between service encounter performance, physical environment performance, novelty, overall satisfaction, and loyalty in the cruise context. The results of structural equation modeling (SEM) analysis showed that service encounter performance and physical environment performance were significant predictors of novelty, which in turn affected overall satisfaction and loyalty. The mediation test indicated that novelty significantly mediated the effect of service encounter performance and physical environment performance on satisfaction; and overall satisfaction significantly mediated the relationship between novelty and loyalty. The relationship between physical environment performance and novelty and the relationship between novelty and overall satisfaction were significant in the high affective commitment group. In addition, the relationship between novelty and loyalty was only significant in the low affective commitment group.
\end{abstract}

Keyword: Affective commitment; Service encounter; Physical environment; Loyalty; Cruise 